\title{
Retrospective study of cases of rupture uterus at tertiary care center in Egypt
}

\section{Laila Ezzat*, Mohamed Salah}

Department of Obstetrics and Gynecology, Faculty of Medicine, Aswan University, Aswan, Egypt

Received: 19 April 2018

Accepted: 23 May 2018

\section{*Correspondence:}

Dr. Laila Ezzat,

E-mail: lailaezzat972000@gmail.com

Copyright: (C) the author(s), publisher and licensee Medip Academy. This is an open-access article distributed under the terms of the Creative Commons Attribution Non-Commercial License, which permits unrestricted non-commercial use, distribution, and reproduction in any medium, provided the original work is properly cited.

\begin{abstract}
Background: Uterine rupture (UR)is one of the most serious obstetrical emergencies necessitating prompt diagnosis and management, as it en-dangers the maternal and fetal life. Uterine rupture (scarred/ unscarred) may occur at any stage of pregnancy. In developed countries, with good antenatal care and good supervision during labour, (UR) has become rare except by dehiscence of a caesarean scar. The objective of present study was to find out risk factors, management, related complications and associated maternal and fetal outcomes with rupture uterus.

Methods: A retrospective study, data files and the case notes was retrieved from the medical records department at Aswan university hospital from January 12013 to December 312013 in the form of data relating to the age, parity, gestational age, method of termination, perinatal outcomes, and related maternal complications.

Results: There were 4284 deliveries during the period under review among them 5 cases of uterine rupture. Thus, the incidence of uterine rupture was $1.1 / 1000$ deliveries. 3 cases $(60 \%)$ of them had no antenatal care at any hospital or primary care center. The risk factors in these cases are in majority $4(80 \%)$ of cases uterine rupture occurred in women with previous scar, 1case $(20 \%)$ of cases uterine rupture occurred in women with none scarred uterus. As regard surgical management 3 cases $(60 \%)$ managed by hysterectomy and 2 cases $(40 \%)$ managed by repair. As regard maternal and fetal outcome all women required blood transfusion. Associated bladder rupture was repaired in two cases (40\%). After excluding fetal wastage before the age of viability, perinatal mortality was $100 \%(5 / 5)$.

Conclusions: Present retrospective analytical study has concluded that rupture uterus is a life-threatening complication. Proper antenatal and intrapartum care, identification of high risk factors, promotion of skilled attendance at birth and institutional delivery are key factors in reduction and early diagnosis.
\end{abstract}

Keywords: Hysterectomy, Maternal morbidity, Perinatal mortality, Rupture uterus

\section{INTRODUCTION}

Uterine rupture (UR) is one of the most serious obstetrical emergencies necessitating prompt diagnosis and management, as it en-dangers the maternal and fetal life. Uterine rupture (scarred/unscarred) may occur at any stage of pregnancy. In developed countries, with good antenatal care and good supervision during labour, (UR) has become rare except by dehiscence of a caesarean scar.
In Egypt, because of poverty, illiteracy and not easy access to antenatal care, delivery is usually accomplished by untrained midwives, dais or by unqualified doctors; (UR) is not uncommon. Incidence of (UR) varies from $0.6 / 1000$ to $250 / 1000$ deliveries. ${ }^{1}$ Its incidence at a particular institution reflects the level of obstetric care provided in that area. It is still a major public health problem in developing countries accounting for 5-18\% of all maternal deaths and a corresponding prenatal mortality rate of $30-95 \%$ in different countries. ${ }^{2}$ 
(UR) may be complete or incomplete depending on whether it opens into the peritoneal cavity or not. Complete (UR) if it communicates with the peritoneal cavity directly and incomplete if it is separated from the peritoneal cavity by the visceral peritoneum and therefore the fetus is not extruded into the abdominal cavity. ${ }^{3}$

Maternal consequences are related to whether there is rupture of an intact uterus or a prior scar of the uterus. Separation of uterine scar following a trial of scar is associated with a lower risk of maternal death compared to spontaneous rupture of an intact uterus. ${ }^{4}$

Spontaneous (UR) of unscarred uterus is associated with higher maternal case fatality rate compared to rupture of a previously scared uterus and it can be as high as 40 to $50 \% .^{5}$ The risk of maternal death due to uterine rupture is $0-1 \%$ in high income countries, but in low income countries it ranges between $5-10 \%{ }^{6}$

Fetal morbidity invariably occurs because of catastrophic hemorrhage leading to fetal anoxia. (UR) and expulsion of the fetus into the peritoneal cavity the chances of fetal survival are rare. If the fetus is alive at the time of rupture, the only chance of continued survival is afforded by immediate diagnosis and delivery by laparotomy. Case fatality rate in rupture uterus may be reduced by early diagnosis, urgent resuscitation and laparotomy. Any form of delay increases the chances of dying from severe bleeding. ${ }^{7}$

The present study was undertaken to evaluate the risk factors, clinical presentation, management, maternal and perinatal outcome of rupture uterus at present hospital and to evaluate the methods to reduce maternal mortality, morbidity and perinatal outcome.

\section{METHODS}

A retrospective study, data files and the case notes were retrieved from the medical records department at Aswan university hospital from January 12013 to December 31 2013 in the form of data relating to the age, parity, gestational age, method of termination, perinatal outcomes, and related maternal complications.

Women with history of previous cesarean section, grand multi-para with good sized fetus (in cephalo-pelvic disproportion), any history of uterine surgery (myomectomy-where uterine cavity was opened), hysteroscopy, hysterotomy, previous history of dilatation and curettage with uterine perforation, history of manual removal of placenta.

If patient came as emergency case the following points were noted: pain abdomen with its duration, history of referral, history of administration of medication, any instrumentation, I.V. fluid administration, history of trauma, rupture of membrane with its duration, cessation of labour pain with its duration, any febrile episode, fetal movement, any vaginal discharge and vaginal bleeding.

The data was entered in the computer for statistical analysis using one proprietary statistical package which is statistical packages for the social science (SPSS).

\section{RESULTS}

There were 4284 deliveries during the period under review among them 5 cases of uterine rupture. Thus, the incidence of uterine rupture was 1.1/1000 deliveries. 3 cases $(60 \%)$ of them had no antenatal care at any hospital or primary care center. The risk factors in these cases are in majority $4(80 \%)$ of cases uterine rupture occurred in women with previous scar, 1 case $(20 \%)$ of cases uterine rupture occurred in women with none scarred uterus this woman had spontaneous uterine rupture at 24 weeks of gestation at none communicating rudimentary horn of unicornuate uterus this woman was 25 years gravida1 para0 who married for 1 year and 7 months presented to the emergency unit with severe lower abdominal pain and minimal spontaneous vaginal bleeding she was in shock with pale, cold, and clammy extremities, a feeble thready pulse of 130 beats/ minute, blood pressure of 80/45 $\mathrm{mmHg}$, and a respiratory rate of $18 /$ minute. Her abdomen was enlarged to 28 weeks in size and was tense with generalized acute tenderness all over. She was resuscitated with intravenous fluids and blood transfusion. Abdominopelvic ultrasound showed fetus of 24 weeks with absent cardiac activity with increased free fluid in the abdominal cavity. emergency laparotomy with the provisional diagnosis of ruptured extrauterine pregnancy with fetal death. During laparotomy, hemoperitoneum of around $3.5 \mathrm{~L}$ of blood with clots was noted. There was complete rupture of the left rudimentary horn of the uterus with the dead fetus lying in peritoneal cavity covered with $1000 \mathrm{~g}$ of clots (Figure 1).

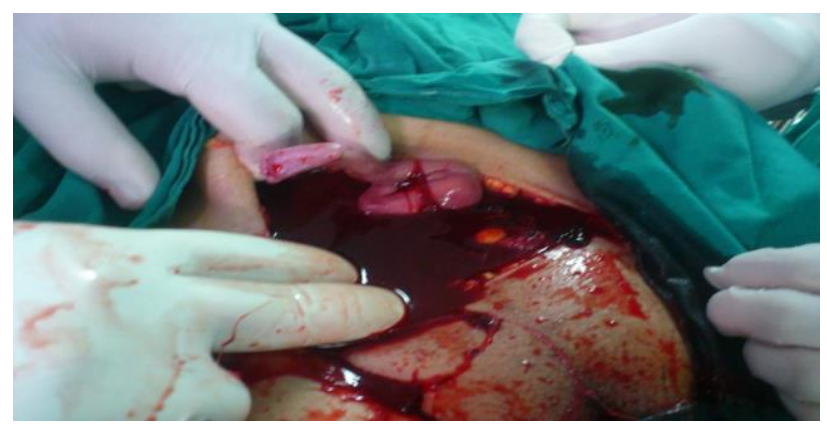

Figure 1: Hemoperitoneum with fetus in abdominal cavity.

A fibromuscular band was seen attached between the unicornuate uterus and rudimentary horn. There was no communication between the rudimentary horn and the main unicornuate uterine cavity. The uterus, lying separate in the pelvis, was soft in consistency, globular and enlarged to a size consistent with eight weeks. (Figure 2). 
The right fallopian tube and ovary were found healthy and were attached normally to the unicornuate uterus.

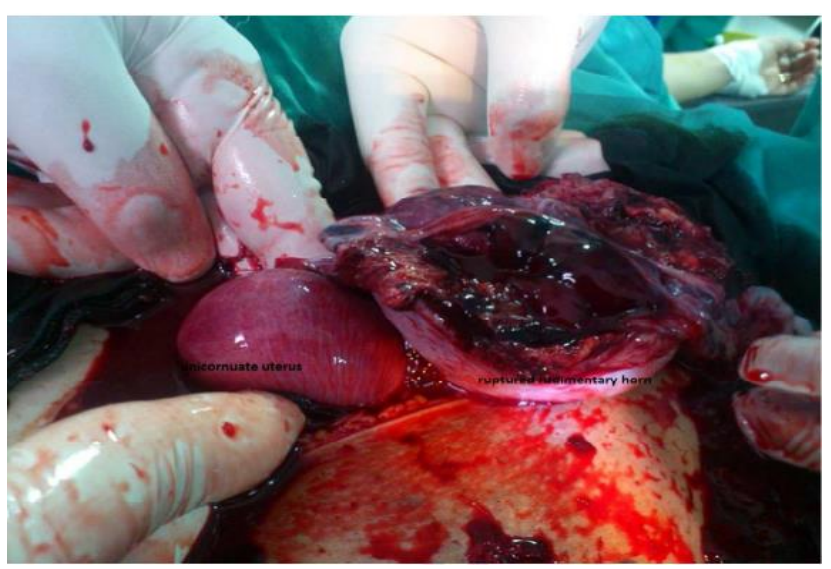

Figure 2: Unicornuate uterus with ruptured rudimentary horn with placenta in its cavity.

The placenta and cord were attached to the uterine horn, the left fallopian tube and left ovary appeared normal, and both were attached to the left rudimentary horn the dead fetus along with the placenta and membranes were removed from the abdominal cavity (Figure 3).

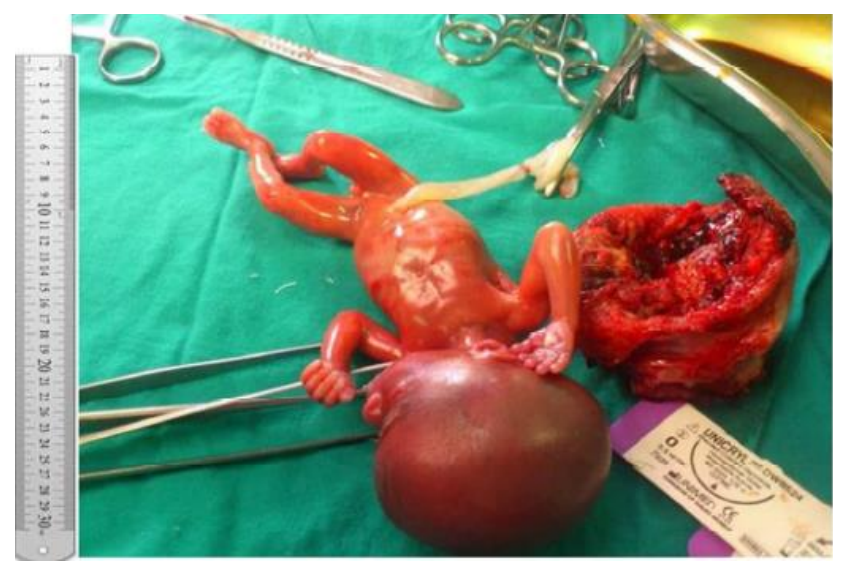

Figure 3: Fetus (24 weeks gestation) with resected rudimentary horn.

Excision of the rudimentary horn and left fallopian tube with conservation of the left ovary was done. Among those scarred uterus 3 cases $(60 \%)$ with previous cesarean (lower segment cesarean section), and 1 case (20\%) with scar of previous surgery (myomectomy). As regard time of rupture 4 cases $(80 \%)$ with intra partum rupture, and 1 case $(20 \%)$ in antenatal period. As regard parity 4 cases (80\%) were multipart and 1case $(20 \%)$ was nullipara.

Table 1: Time of rupture.

\begin{tabular}{|l|l|l|}
\hline Time of rupture & No. & Percentage \\
\hline Antenatal period & 1 & 20 \\
\hline Intrapartum & 4 & 80 \\
\hline Total & 5 & 100 \\
\hline
\end{tabular}

As regard surgical management 3 cases $(60 \%)$ managed by hysterectomy and 2 cases (40\%) managed by repair.

Table 2: Type of scar rupture during labour.

\begin{tabular}{|l|l|l|}
\hline Type of scar rupture & No. & Percentage \\
\hline Previous lower segment scar & 3 & 60 \\
\hline Previous myomectomy & 1 & 20 \\
\hline Total & 4 & 80 \\
\hline
\end{tabular}

As regard maternal and fetal outcome all women required blood transfusion. Associated bladder rupture was repaired in two cases $(40 \%)$. After excluding fetal wastage before the age of viability, perinatal mortality was $100 \%(5 / 5)$.

Table 3: Type of surgical management.

\begin{tabular}{|l|l|l|}
\hline Type of surgical management & No. & Percentage \\
\hline Hysterectomy & 3 & 60 \\
\hline Repair & 2 & 40 \\
\hline Total & 5 & 100 \\
\hline
\end{tabular}

In $2 / 5(40 \%)$ women: there was intrauterine death while another $3 / 5$ (60\%) had early neonatal death. None of the fetuses found in peritoneal cavity following rupture of uterus was alive.

Table 4: Maternal and fetal outcome.

\begin{tabular}{|l|l|l|}
\hline Maternal and fetal outcome & No. & Percentage \\
\hline Maternal blood transfusion & 5 & 100 \\
\hline Associated bladder rupture & 2 & 40 \\
\hline Perinatal mortality & 5 & 100 \\
\hline
\end{tabular}

\section{DISCUSSION}

UR still remains one of the serious obstetric complications. Lack of health information, illiteracy, poor antenatal care, poverty, home deliveries by traditional birth attendants and delay in referrals all contribute to (UR). ${ }^{8}$

UR during labor is more threatening than that occurring in pregnancy, because shock is greater, and infection cannot be avoided. ${ }^{9}$ Its incidence varies from 1:149 to $1: 2966 .{ }^{10}$

In present study total number of deliveries at Aswan university hospital from January 1, 2013 to December 31, 2013 was 4284 Total number of rupture uterus during same period was 5 .

The incidence of rupture uterus was $1.1 / 1000$ or $0.1 \%$ this is due to complicated cases from peripheral hospitals are referred here. Incidence of rupture uterus varies greatly according to centre to centre where cases have been being reported. 
In present study, rupture from scarred uterus occurred in 4women (80\%) out of these 3 women (60\%) had rupture of previous lower segment caesarean scar, 1 woman (20\%) had rupture of previous myomectomy. The results of present study are consistent with those of Manju et al who reported that rupture from scarred uterus occurred in 10 women $(71.4 \%)$, out of these 9 women $(64.2 \%)$ had rupture of previous caesarean scar, 2 women (14.2\%) had rupture of previous classical caesarean. ${ }^{2,11}$

So, in women with previous LSCS, for deciding mode of delivery, the primary indication for and type of previous caesarean section must be meticulously screened, the integrity of the scar to be assessed and cephalo-pelvic disproportion to be ruled out so as to avoid rupture uterus. In present study there was 1 case $(20 \%)$ of rupture uterus occurs in non-scarred primigravid uterus this is a rare case due to congenital anomaly in the uterus.

It was noted that absent fetal heart sound was the commonest feature in 3 out of 5 cases. In present study fetal heart sound was present in 2 cases with fetal distress and during caesarean section partial rupture of the uterus was found and died after few hours from delivery so perinatal mortality was $100 \%$.

Gardeil F during an analysis of 26 cases of rupture of scar observed that 16 cases were of incomplete uterine rupture with the fetus still in utero and varying degree of separation of scar present. $^{12}$ Ibha $\mathrm{K}$ et al noticed that clinical feature were extremely variable and most of the women presented with more than one feature. ${ }^{13}$

The present incidence of perinatal mortality was in close to the reports of Khan $\mathrm{S}$ et al and Malik HS. ${ }^{14,15}$ The decision to perform uterine repair or hysterectomy in cases of uterine rupture is influenced by the parity of the patient, extent of the rupture and general condition of the patients.

Repair of the uterine rupture should be performed in women with scar rupture in whom the tear is most often linear. In present study the incidence of subtotal hysterectomy to repair was $60 \%$ vs $40 \%$. Thakur et al evaluated outcome in women undergoing subtotal hysterectomy versus repair in extremes of uterine rupture. ${ }^{16}$

They found that the maternal mortality was significantly higher in women who underwent repair $(46 \%$ versus $20 \%$ ). Few resources and health care centers in remote areas, lack of awareness and education regarding regular antenatal checkups, delay in diagnosing cases and referring to higher centers, time lost in travel were the major hurdles that authors identified in present study.

\section{CONCLUSION}

This retrospective analytical study concluded that most common cause of rupture uterus was neglected prolonged second stage of labor followed by scarred uterus. Hence, authors have recommended institutional labor for high risk cases with proper management of labor by experience staff with use of portogram.

A lot of the women had no antenatal check-up and/or were managed initially by untrained personnel. Thus, in most of the cases, uterine rupture is a preventable complication. Antenatal and intranatal care, identification of high risk cases and education of the people about supervised pregnancy and delivery will reduce the occurrence of (UR).

Funding: No funding sources

Conflict of interest: None declared

Ethical approval: The study was approved by the Institutional Ethics Committee

\section{REFERENCES}

1. WHO systematic review of maternal mortality and morbidity: The prevalence of uterine rupture. BJOG. 2005;112:1221-8.

2. Flamm BL. Once a caesarean, always a controversy. Obstet Gynaecol. 1997;90:312-5.

3. Padhye SM. Rupture of pregnant uterus- a 20 years review. Kathmandu University Med J. 2005;3:234-8.

4. Flamm BL, Anton D, Goings JR, Newman J. Prostaglandin E2 for cervical ripening: a multicentre study of patients with prior caesarean delivery. Am J Perinatol. 1997;14:157-60.

5. Eden RD, Parker RT, Gall SA. Rupture of the pregnant uterus: a 53-year review. Obstet Gynecol. 1986;68:671-4.

6. Rahman J, Al-Sibai MH, Rahman MS. Rupture of the uterus in the labour. A review of 96 cases. Acta Obstet Gynecol Scand. 1985;64:311-5.

7. Leung AS, Leung EK, Paul RH. Uterine rupture after previous caesarean delivery: maternal and fetal consequences. Am J Obstet Gynecol. 1993;169:94550.

8. Malik HS. Frequency, predisposing factors and fetomaternal outcome in uterine rupture. J Coll Physicians Surg Pak. 2006;16:472-5.

9. Miller DA, Goodwin TM, Gherman RB, Paul RH. Intrapartum rupture of the unscarred uterus. Obstet Gynecol. 1997 May;89(5):671-3.

10. Rachagan SP, Raman S, Balasundram G, Balakrishnan S. Rupture of the pregnant uterus - 21year review. Aust Nz J Obstet Gynecol. 1999;31:3740.

11. Arora M, Jindal S, Gupta S. Retrospective study of cases of rupture uterus. Int $\mathbf{J}$ Reprod Contracep Obstet Gynecol. 2017 Apr 27;6(5):1900-4.

12. Gardeil F, Daly S, Turner MJ. Uterine rupture in pregnancy reviewed. Eur J Obstet Gynecol Reprod Biol. 1994;56:107-10.

13. Kumari I, Goel P, Shegal A, Devi K. Rupture of gravid uterus: Experience at an urban medical centre 
in Northern India. J Obstet Gynecol India. 2003;6(53):558-62.

14. Khan S, Parveen Z, Begum S, Alam I. Uterine rupture: a review of 34 cases at Ayub Teaching Hospital Abbottabad. JAMC. 2003;15(4):50-2.

15. Malik HS. Frequency, predisposing factors and fetomaternal outcome in uterine rupture. J Coll Physicians Surg Pak. 2006;16:472-5.
16. Thakur A, Heer MS, Thakur V. Subtotal hysterectomy for uterine rupture. Int $\mathrm{J}$ Gynecol Obstet. 2001;74:29-33.

Cite this article as: Ezzat L, Salah M. Retrospective study of cases of rupture uterus at tertiary care center in Egypt. Int J Reprod Contracept Obstet Gynecol 2018;7:2993-7. 